\title{
The impact of infant feeding patterns on infection and diarrheal disease due to enterotoxigenic Escherichia coli
}

\author{
Kurt Long, Ph.D., ${ }^{(1)}$ Edgar Vasquez-G aribay, ${ }^{(2)}$ John Mathew son, Ph.D., ${ }^{(3)}$ \\ Javier de la Cabada, M.D. ${ }^{(4)}$ Herbert D uPont, M.D. ${ }^{(5)}$
}

\begin{abstract}
Long K, Vasquez-Garibay E, Mathewson JJ, de la Cabada FJ, DuPont HL. The impact of infant feeding patterns on infection and diarrheal disease due to enterotoxigenic Escherichia coli. Salud Publica Mex 1999;41:263-270.
\end{abstract}

\begin{abstract}
A bstract
Objective. Determine the impact of dietary risk factors on patterns of infection by heat labile toxin-producing Escherichia coli (LT-ETEC). Materials and methods. $\mathrm{N}$ inety-eight infants were followed from birth for one year in G uadalajara, Mexico, beginning in august of 1986. Stool and breast milk samples were collected weekly from infants and their mothers, respectively. Mothers were also inter viewed on a weekly basis regarding the health of the infants. Parametric hazard models were fit to durations of different LT-ETEC disease states determined through the analysis of stools. The child's consumption of supplemental fo ods and liquids as well as specific levels of LT-ETEC -specific breast milk antibodies were included in each model as timevarying covariates. Results. The hazard of LT-ETEC asymptomatic infection increased 400 percent among children who received oats gruel (hazard rate $=4.01 ; 95 \%$ CI 2.77-5.24). The duration of infection was reduced if the child had had a previous LT-ETEC diarrheal episode (2.12; $95 \% \mathrm{Cl} 1.74-2.49)$ but was prolonged if the child consumed herbal teas $(0.53 ; 95 \% \mathrm{Cl} 0.27-0.7)$. Herbal teas and high LT-ETEC-specific breast milk antibody levels each reduced the hazard of symptomatic infection by ninety percent. Symptomatic episodes became asymptomatic more rapidly if a child was given rice water. Conclusions. Specific weaning foods increase the risk of infection. Breastmilk antibodies and liquid infusions reduce diarrheal disease and infection duration.
\end{abstract}

Key words: antibodies; breast-feeding; diarrhea, infantile; Escherichia coli; hazards models; weaning; Mexico
Long K, Vasquez-Garibay E, Mathewson JJ, de la Cabada FJ, DuPont HL.

El impacto de las modalidades de alimentación infantil en la infección y en las enfermedades diarreicas por Escherichia coli enterotoxigénica.

Salud Publica Mex 1999;41:263-270.

\section{Resumen}

Objetivo. D eterminar el impacto de los factores dietéticos sobre patrones de infección por Escherichia coli enterotoxigénica productora de la toxina lábil (ECET-TL). Material y métodos Se reclutaron 98 infantes al nacer, en agosto de 1986; se hizo seguimiento durante un año. En visitas semanales se recolectaron muestras de heces de los niños y una muestra de leche de las madres; éstas fueron entrevistadas so bre la morbilidad del niño. Se ajustaron modelos de hazard a la estancia de tiempo de los niños en los distintos estadios de la enfermedad causada por el ECET-TL. La ingestión de comida suplementaria y de líquidos por el niño, así como los niveles de anticuerpos específicos contra ECET, se incluyeron como variables en los modelos. Resultados. El riesgo de infección asinto mática aumentó significativamente entre los niños que comían avena (tasa de hazard $=4.01$; IC $95 \%$ 2.77-5.24) y su duración se redujo si el niño tenía un episodio previo de diarrea causado por ECET $(2.12$; IC 95\% 1.74-2.49) pero se prolongó si el niño ingería tés (0.53; IC $95 \%$ 0.27-0.7). Tanto los tés como la ingestión de altos niveles de anticuerpos específicos contra ECET en la leche materna redujeron el riesgo de infecciones sintomáticas. LoS episodios sintomáticos pasaron a ser asintomáticos más rápidamente cuando el niño ingería agua de arroz. Conclusiones Las comidas específicas de destete aumentan el riesgo de infección. Los anticuerpos de la leche materna y los líquidos reducen la duración del episodio de diarrea.

Palabras claves: anticuerpos; alimentación con leche materna; diarrea, infantil; Escherichia coli; modelos de hazard; destete; México

(1) Departamento de N utrición y Salud del N iño, Instituto Nacional de Salud Pública, Cuernavaca, Morelos, México.

(2) Departamento de Pediatría, N uevo Hospital Civil, Guadalajara, México.

(3) D epartment of Microbiology, University of Texas Medical School, Houston, TX.

(4) Departamento de Enfermedades Infecciosas, Hospital G eneral de 0 ccidente, Guadalajara, México.

(5) Department of Internal Medicine, St. Lukes Hospital, Houston, TX.

Fecha de recibido: 4 de agosto de 1998 • Fecha de aprobado: 25 de marzo de 1999 Solicitud de sobretiros: Dr. Kurt Long, Instituto N acional de Salud Pública. Av. Universidad 655, Santa Maria A huacatitlán, 62508 Cuernavaca, Morelos, México. 
$\mathbf{R}$ esearch on the impact that infant feeding patterns $R$ have on diarrheal disease-related morbidity and mortality have identified breast-feeding duration and the timing of supplemental food introduction as important behavioral determinants which structure this relationship. ${ }^{1}$ Similarly, efforts to define specific biological mechanisms underlying these relationships have identified a large number of nutritional, ${ }^{2-10} \mathrm{mi}-$ crobiological $^{11-19}$ and immunological factors ${ }^{20-33}$ which are associated with specific patterns of diarrheal disease morbidity and mortality. However, this body of research has not systematically addressed how these different factors temporally interact during specific stages of the disease and so cannot determine how such mechanisms contribute to the overall outcome of the infection. Instead, the majority of studies merely calculate the risk of diarrheal disease among children classified according to age and feeding mode. This approach, by ignoring the biological spectrum of the disease, is unable to identify which factors constitute exposure risk for diarrheal disease among children and which factors merely modify the disease process. As a result, the measures of association between reported risk factors and disease outcome produced by these studies may be somewhat biased and uninterpretable.

It is important to consider alternative approaches which can analytically treat the multiple stages and competing outcomes of infections in a more temporal fashion. Hazard models provide such an alternative since they are concerned with determining the probability that an event or multiple events will occur in a specified time. As such, the impact different risk factors have on the interval of time for each specific state and on the probability of a specific outcome for that interval can be determined. The definition of these processes would provide important insights into how public health programs concerned with diarrheal disease reduction could be made more effective.

In this paper a hazard analysis of transitions between states of infection and disease due to heat-labile toxin-producing Escherichia coli (LT-ETEC) in young children is carried out to determine the impact specific feeding mode risk factors have on each of these states and on the overall epidemiology of the disease. This analysis shows that the child's developing immune response limits the duration of infection and diarrheal disease independently of passive immunity. Simultaneously, the mother's provision of astringent liquids to the infant limits the onset and duration of diarrheal episodes but also lengthens the duration of asymptomatic infections.

\section{Materials and methods}

\section{Enrollment of children and follow-up}

As reported earlier, ${ }^{34} 98$ women-infant pairs were enrolled after the birth of the child in the Mexican city of Guadalajara between the months of august 1986 and february 1987 and subsequently visited two to three times a week by project personnel for periods ranging from 3 to 50 weeks. Breast milk samples were collected once a week from the mother. A stool sample was collected during a diarrheal episode and once a week from children without symptoms. For the purpose of this study, diarrhea was defined as four or more bowel movements in 24 hours with a liquid or semi-liquid consistency, as reported by the mother. An episode was considered to be ended when a child showed no symptoms for 72 hours and the stools were normal in consistency.

Mothers were asked to describe the frequency and intensity of breast-feeding lapses, and the frequency, types and manner of preparation of all supplemental foods and liquids given to the infant in the previous 24 hours. Every three months, household members were also interviewed about the number, ages, and income of all household members, the education levels of the child's parents, the sources of drinking water, and the types of bathroom utilized in the house.

\section{Microbiologic and immunologic studies}

All stool samples were inoculated on MacConkey agar and incubated overnight at $37^{\circ} \mathrm{C}$. Five lactose positive colonies from each plate were selected and tested for the production of heat-labile enterotoxin using the Y-1 adrenal cell assay as reported by Sack et al. ${ }^{35}$

Anti-heat-labile toxin activity was then determined in milk samples using a GM1 enzyme-linkedimmunosorbant capture assay as described by Long et al. ${ }^{34}$ Briefly, a 1:100 dilution of the ganglioside receptor for the toxin was incubated in a 96-well polystyrene plate followed in succession by a 1:1,000 dilution of the B-component of E. coli heat-labile enterotoxin (courtesy of J. Franz, Norden Laboratories, Lincoln NB, and J. Clements, Tulane University, New Orleans LA), a two-fold dilution (1:2 and 1:10) of the breast milk sample and, finally, a 1:300 dilution of goat alkalinephosphatase antibody specific for the alpha-chain of human immunoglobulin A. An antibody standard was obtained by the same procedure except that a rabbit anti-cholera toxin was used in place of a breast 
milk sample and a goat anti-rabbit alkaline phosphatase conjugate was used in place of the goat anti-human conjugate in the final step.

\section{Conceptual framework for statistical analysis}

In this study, an asymptomatic infection was defined as encompassing a period when a child had one or more LT-ETEC-positive stools but had no associated symptoms. A symptomatic LT-ETEC infection was defined as one or more LT-ETEC -positive stools associated within 72 hours of the initiation of diarrheal symptoms.

Episodes of asymptomatic and symptomatic infection represent components of the biological spectrum of the infection. Children's disease experience are, therefore, conceptualized as paths through the three intercommunicating states of non-infection, asymptomatic LT-ETEC infection and symptomatic infection (figure 1). In the formal analysis, the transition from an initial state of non-infection at birth to a state of asymptomatic infection is designated as model 1. Once asymptomatically infected, the child can make a transition to a state of non-infection designated as model 2 or make a transition to the competing state of symptomatic infection designated as model 3 (figure 1). Model 4 denotes the transition made by children from a state of symptomatic infection to a state of asymptomatic infection while model 5 denotes transitions from symptomatic infection to a state of non-infection. Transitions between non-infection and symptomatic infection were too few in number to be analyzed.

The child can pass through a similar set of transitions if he/ she becomes reinfected. The analysis of transitions for models 1 and 2 is carried out separately for the first, second and third episodes to determine if specific dietary and immune response factors have the same impact in each sequential episode. The analysis of the transition between asymptomatic infections and symptomatic infections (model 3) and between symptomatic infection and asymptomatic infection (model 4 ) is carried out on all transitions combined due to the small sample sizes.

Right-censoring mechanisms are used for episodes of non-infection if the child leaves the study before becoming infected, or for asymptomatic and symptomatic episodes if the child continues to have LT-ETEC-positive stools or continues to have diarrhea upon leaving the study. Durations until one of two competing outcomes are also set as right censored

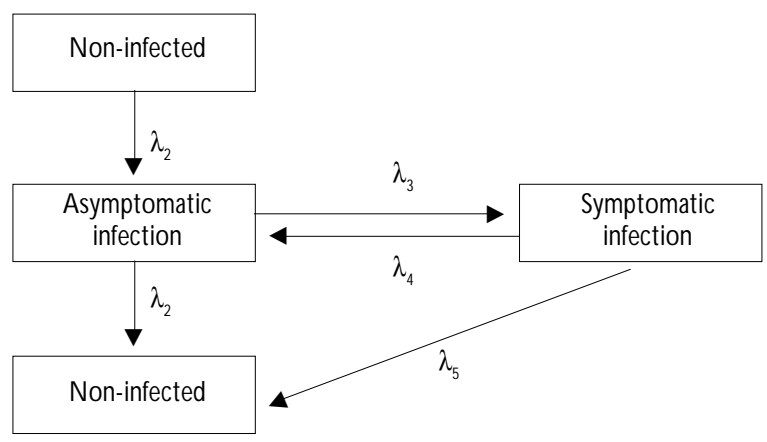

Figure 1. Multi-state hazard model of transitions BETWEEN DIFFERENT STAGES OF LT-ETEC INFECTION. $\lambda_{1}$ $\lambda_{2}$ Hazard transitions MOdelled IN THE ANALYSIS

when durations until the opposite outcome is being analyzed.

\section{Proportional Hazards model and estimation}

The state space of transitions is to be denoted by $S$, and $t_{\mathrm{ij}}$ is to denote the time spent in an initial state $i$ ( $i=$ $1,2, \ldots, p)$ before existing to state $j(j=1,2, \ldots, p)$. Continuous Time Models, a general multi-state program used to carry out the parametric analysis of these transitions, ${ }^{36-38}$ specifies the hazard function in the following way:

$$
\begin{gathered}
h_{i j}\left(t_{i j} \mid\{x(u)\}_{0}^{\infty}, t_{j-1} \theta\right)=\exp \left\{\gamma_{i j 0}+Z\left(t_{i j}\right.\right. \\
+\tau(j-1)) \beta_{i j}+\left(\frac{t_{i j}^{\lambda i j}-1}{\lambda_{1 j}}\right) \gamma_{1 j} \\
+\left(\frac{t_{i j}^{\lambda 2 j-1}}{\lambda_{2 j}}\right) \gamma_{\left.\gamma_{2 j}\right\}, \lambda_{1 j}<\lambda_{2 j}}
\end{gathered}
$$

In this specification $t$ is the calendar date of entry into state $i, x$ is the vector of independent variables included in the model and $\mathrm{Z}$ can potentially include any known functions of this vector. Different forms of time duration are also specified by setting $\lambda_{i j}$ and $\gamma_{i j}$ to one or zero. Conventional likelihood ratio methods are then used to compare the fit of each constrained model against more general models. ${ }^{38}$

Dummy covariates were included in the models to capture the impact of each supplemental food and liquid given to the infants, the four seasons of the study period, the onset and duration of respiratory illnesses and the presence of mucus or blood in stools. The number and durations of breast-feeding bouts, the assigned levels of antibodies specific for LT-ETEC and the fre- 
quency of stool evacuations per day were introduced into the model as quantitative variables. The impact of the infant's developing immune system was included in the model through the use of following proxy measures: the age of child in weeks, the number of previous colonization events or LT-ETEC-positive diarrheal episodes, the time since these previous events, and the time since the mother stopped breast-feeding. Potential confounding socio-economic covariates included the parents' age, level of education, number of household members, family income, sources of household drinking water, types of household bathrooms and house construction material.

Survival curves were estimated for each of the transitions involved in LT-ETEC infection based on the hazards models selected for that transition. Separate curves were estimated for a model without covariates and for different levels of covariates included in the best-fitting model.

\section{Results}

\section{Patterns of LT-ETEC infection and disease}

A total of 104 bouts of LT-ETEC infection were recorded among the 98 infants followed during the study period producing an overall rate of six infections per child-year. Fifty-two percent of the children who en- tered the study at birth had at least one infection, 22\% had two infections and $11 \%$ had three. Eighty-three percent of all episodes remained asymptomatic. As reported in an earlier paper, ${ }^{34} 0,10$ and 22 percent of infections were symptomatic among babies receiving only breast milk and teas, among babies receiving both breast milk and formula and among strictly formulafed babies, respectively.

The median duration of time until the onset of asymptomatic infection following birth or after the last infection was 97 days among all children. Among infected children the median duration until the onset of symptoms was approximately 7 days while the median duration of the diarrheal episode was approximately four days (table I). The median duration until the onset of infection was significantly different when the children were classified according to age based on the logrank test for differences between survival curves (table I). There were no other significant differences in median duration for other stages of the infection when children were classified by age or for any of the stages when the durations were classified by episode number.

\section{Multi-state Hazards analysis}

The number of children passing through the different transition between the three states are given in tables II and III along with the results of the hazards analysis.

Table I

Median duRATIONS UNTIL THE ONSET AND END OF ASYMPTOMATIC AND SYMPTOMATIC LT-ETEC* INFECTIONS BY SELECTED VARIABLES

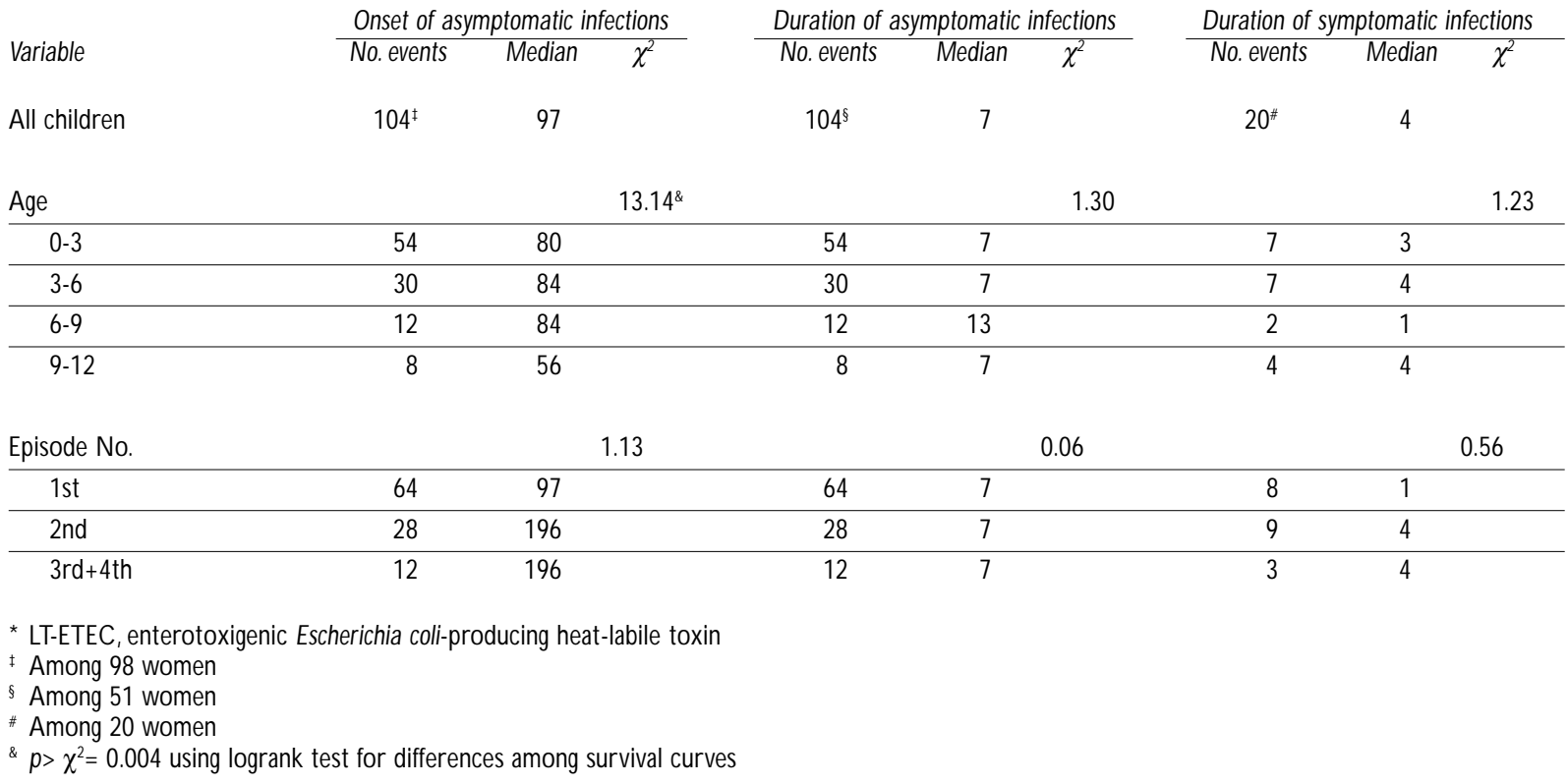


The hazard for the onset of the first asymptomatic infection (model 1) is time-invariant and increases 401 percent (95\% CI 2.77-5.24) among children who consume oats gruel relative to children who do not and 504 percent (95\% CI 5.32-6.41) during the rainy season relative to other seasons (table II). No covariates were found to affect the hazard for the second or as third and fourth combined colonization events.

The risk of terminating both the first and second asymptomatic infections (model 2) increases through time. Children who consumed herbal tea had a 50\% reduction (95\% CI 0.27-0.7) in the hazard of ending the infection compared to children who did not (table II). This hazard increased more than 218 percent $(95 \%$ CI 1.91-2.44) for each increment in the mother's level of education and 212 percent (95\% CI 1.74-2.49) for each additional symptomatic LT-ETEC infection the child had previously experienced. The length of infection is longest for children who consume tea and who have had no previous symptomatic infections.

The hazard for the onset of diarrhea among asymptomatically infected infants increases through time (model 3). A unit increment in the level and amount of LT-ETEC-specific immunoglobulin A antibodies a baby ingests in a day decreases the hazard of symptomatic diarrhea among infected infants by 32 percent $(95 \% \mathrm{CI}$ $0.57-0.8$ ) (table III). There is approximately a 90 percent reduction in this hazard (95\% CI 0.067-0.62) among children who received tea infusions and a 94 percent reduction (95\% CI 0.007-0.49) among children whose mothers had completed a secondary level of education relative to those who had not. The estimated survival curve for the onset of symptoms is very prolonged for children who consume tea and who are breast-fed

\section{Table II}

\section{Covariates INCLUDEd IN MOdelS ADJUSTED TO TRANSITION BETWEen STATES OF ASYMPTOMATIC LT-ETEC* INFECTIONS AND NON-INFECTION}

\begin{tabular}{|c|c|c|c|c|}
\hline \multirow[b]{2}{*}{ Variable } & \multicolumn{2}{|c|}{ Model $1^{\S \#}(n=98)$} & \multicolumn{2}{|c|}{ Model $2^{\ddagger 5 \AA}(n=51)$} \\
\hline & Hazards rate & P-value & Hazards rate & P-value \\
\hline Rainy season & $5.8 \quad(5.32$ to 6.41$)$ & 0.00 & & \\
\hline Avena & $4.01(2.77$ to 5.24$)$ & 0.04 & & \\
\hline Herbal tea & & & $0.53(0.27$ to 0.70$)$ & 0.001 \\
\hline Education of mother & & & 2.18 (1.91 to 2.44$)$ & 0.00 \\
\hline N o. previous symptomatic LT-ETEC infections & & & 2.12 (1.74 to 2.49$)$ & 0.05 \\
\hline $\begin{array}{l}\text { * LT-ETEC, enterotoxigenic Escherichia coli-pro } \\
\text { Defined in text and in figure } 1 \\
\text { Model includes parent's age, child's age, hous } \\
\text { C Covariates included in quadratic model } \\
\text { Covariates included in W eibull model }\end{array}$ & $\begin{array}{l}\text { ing heat-labile toxin } \\
\text { Id income, water sou }\end{array}$ & of tolet & onfounding & \\
\hline
\end{tabular}

Table III

\section{CoVARIATES INCLUDED IN MODELS ADJUSTED TO TRANSITION BETWEEN ASYMPTOMATIC AND SYMPTOMATIC LT-ETEC* INFECTIONS}

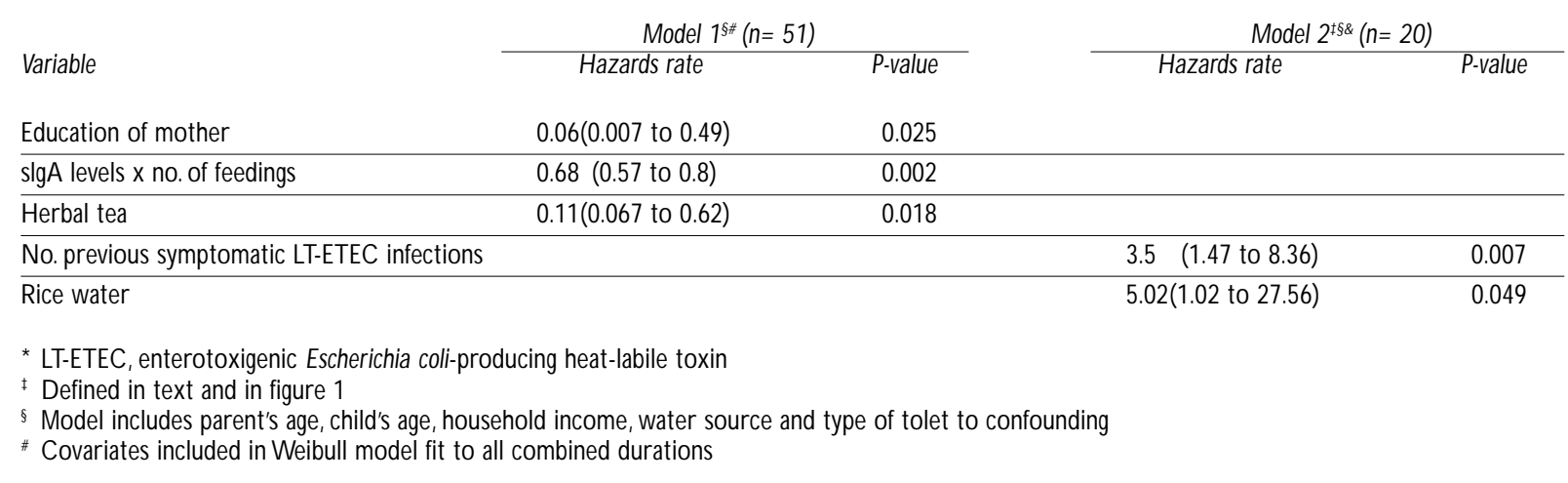


three times a day again and is dramatically shortened for children who receive no tea and who are not breast-fed (figure 2).

The hazard that a symptomatic infection will become asymptomatic decreases through time (model 4). Children with diarrhea who received rice water had a 500 percent greater hazard (95\% CI 1.02-27.56) that their episode would become asymptomatic when compared to children with diarrhea who did not receive this liquid (table III). This hazard increased almost 350\% (95\% CI 1.47-8.36) for children who had a previous symptomatic LT-ETEC infection.

The hazard that a child with diarrhea will become non-infected decreases through time. No covariates were found to significantly improve this model.

\section{Discussion}

This hazards analysis has defined the relative impact that different infant dietary factors have on the biological spectrum of LT-ETEC infections and so has clarified how the interaction of these factors determines the outcome of the infection. This process is initiated by the introduction of easily-contaminated, high carbohydrate content foods as indicated by the impact these factors have on the hazard of initial LT-ETEC colonization. This finding provides direct support for the hypothesis ${ }^{11-16,39-40}$ that such foods serve as vehicles for the introduction of enteric pathogens. However, the continued importance of the rainy season variable sug-

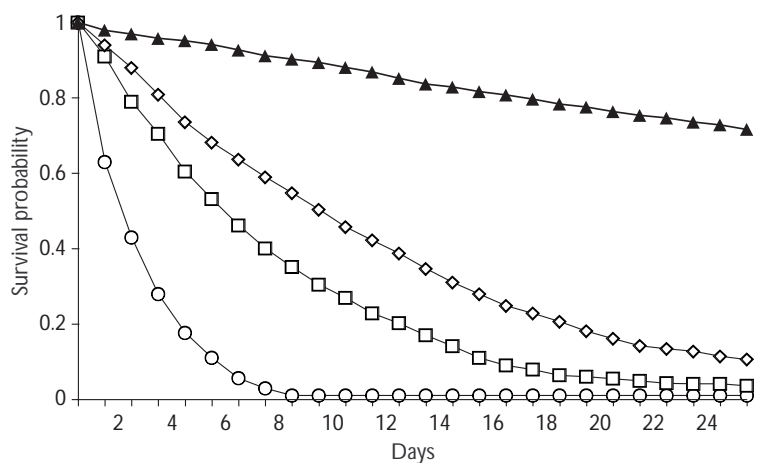

Figure 2. Estimated SURVIVAL CURVES fOR TRANSITIONSBETWEEN ASYMPTOMATIC INFECTION AND SYMPTOMATIC INFECTION (MODEL 3) BY CONSUMPTION OF TEA AND BY NUMBER OF BREAST FEEDS BASED ON THE HAZARDS MODEL. $\square$ No TEA + 3 BREAST FEEDS; $\bigcirc$ No TEA + No BREAST FEEDS; $\nabla$ TEA +3 BREAST FEEDS; $\diamond$ TEA + NO BREAST FEEDS gests that the pathogen is being introduced through other transmission routes during this season.

The total amount of LT-ETEC-specific breast-milk antibodies the child receives per day does not affect this hazard but does reduce the risk that these infections will become symptomatic. Glass et al. ${ }^{20}$ and Walterspiel et al. ${ }^{41}$ have also found that breast-milk antibodies specific for cholera and Giardia lamblia, respectively, protect against diarrhea in children infected with these pathogens but do not protect against the onset of the infection.

Herbal teas similarly reduce the risk that an infection will become symptomatic but also prolong the length of time the child remains infected. Camomile tea (Matricaria chamomilla L.), the tea most frequently given to the study children, has been reported to reduce gastro-intestinal motility. ${ }^{42}$ This effect is thought due to the impact that teas have on the smooth muscle lining of the gastro-intestinal tract, an effect similar to that produced by anticholinergic drugs. As a result, the infected child who consumes tea cannot develop a diarrheal response. This inability to develop a diarrheal response may also explain why LT-ETEC infections in children who consume teas is more prolonged. Diarrhea is thought to be a mechanism by which the bowel rids itself of pathogenic microorganisms. The reduction of a diarrheal response by teas and anticholinergic agents may, therefore, interfere with intestinal tract's ability to eliminate the infecting organism and so prolong the infection. ${ }^{43}$

The two-foldincrease in the risk that an asymptomatic infection will end if the child has had a previous symptomatic LT-ETEC infection may relate to a large number of clinical trials carried out to test the immunogenicity of specific ETEC virulence factors. These studies ${ }^{24-25,44-45}$ have found that animals or human subjects who were previously infected with LT-ETEC excreted the same challenge strain for significantly shorter periods than did non-immunized individuals. However, in our study the measurement of previous exposure to pathogen virulence factors was only indirect making it difficult to directly attribute a decrease in asymptomatic infection durations to increased immunity.

The finding that each increment in the mother's level of education is associated with a two-fold increase in the risk of ending an asymptomatic infection and a $90 \%$ decrease in the competing risk of diarrheal disease onset relates to results found in the Philippines ${ }^{46}$ and in Malaysia. ${ }^{47}$ These studies found that increases in maternal education led to reductions in infant diarrhea and mortality due to the more educated mother's improved excreta disposal practices and her more ef- 
fective use of piped water. These practices may be reducing the pathogen inocula size the child ingests and limiting the continued reintroduction of the pathogen.

The finding that rice water can significantly reduce the length of a diarrheal episode is partly supported by studies examining the impact of rice-based solutions on diarrheal disease. ${ }^{48-49}$ These studies found that such solutions significantly reduced stool output among children who have high stool output diarrhea. Wapnir and Lishit ${ }^{50}$ found that when the osmolarity of oral rehydration solutions is reduced there is a significant increase in net intestinal water absorption. This increase may be responsible for the reduced stool output seen in children with diarrhea who are given rice water. However, no studies have addressed whether children remain asymptomatically infected after treatment with such solutions. It may be possible that intestinal water absorption is so great that intestinal motility may be reduced leading to a reduced ability to eliminate the pathogen.

The increased hazard that symptomatic episodes will become asymptomatic among children who have had a previous symptomatic LT-ETEC infection may also reflect the development of a protective immune response. The numerous clinical trials and animal models of LT-ETEC infection, mentioned, earlier have shown a similar protective effect. Svennerholm et al. ${ }^{24}$ for example, have shown that rabbits previously exposed to a particular strain of LT-ETEC had significantly shorter diarrheal disease episodes then unexposed rabbits when rechallenged with the same strain. The overall amount of breast milk antibodies the child receives per day does not appear to have an impact on these diarrheal disease durations. This finding contrasts with a number of studies which have shown breast-feeding in general to reduce the risk of persistent diarrhea. ${ }^{51-52}$

Overall, these findings suggest that there may be a large number of asymptomatic infections prevalent among pediatric populations in developing countries relative to symptomatic infections. These results also suggest that the well-established protective role of both passive and active immunity found in many epidemiological studies may be due principally to the prevention of disease onset and not to the prevention of infection. Similarly, both traditional beverages and beverages of more contemporary medical use do seem to reduce diarrheal disease onset and/or reduce episode duration. However, the physiological mechanisms responsible for these effects can also prolong asymptomatic infections, a decidely negative effect given the increasing evidence which shows poor growth responses associated with asymptomatic infections among young children..$^{53}$
These findings have important implications for health programs in developing countries. Diarrheal disease control programs should continue to educate mothers regarding the hygienic preparation and storage of foods and the importance of breast-feeding. It is also important that the development of vaccines specific for diarrheal pathogens be continued. However, this study suggests that public health programs should consider interventions which curtail or modify the use of traditional teas which may be prolonging asymptomatic infections. The coordinated application of these different programs could dramatically improve the health and survival of children in countries such as Mexico.

\section{References}

1. Kovar MG, Serdula MK, Marks JS, Fraser DW. Review of the epidemiological evidence for an association between infant feeding mode and infant health. Pediatrics 1984;74(suppl):615-638.

2. Scrimshaw N S, Taylor CE, Gordon JE. Interactions of nutrition and infection. Geneva:W orld Health $O$ rganization, 1968.

3. Beaton GH, Martorell R,A ronson KJ, Edmonston B, McC abe G, Ross AC et al. Effectiveness of vitamin A supplementation in the control of young child morbidity and mortality in developing countries.ACC/SCN State of the Art Series N utrition Policy D iscussion Paper N 0. 13. United N ations, 1993.

4. Keusch G T. Micronutrients and susceptibility to infection.Ann N Y Acad Sci 1990; 587:181-188.

5. Sommer AC. Vitamin A status, resitance to infection and childhood mortality. Ann NY Acad Sci 1990; 587:17-23.

6. Sazawal S, Black RE, Bhan MK Jalla S, SinhaA Bhandari N . Efficacy of zinc supplementation in reducing the incidence and prevalence of acute diarrhea - A comunity-based, double blind,controlled trial. Am J Clin N utr 1997;66(2):413-418.

7. Ruel MT, Rivera JA, Santizo MC , Lonnerdal B, Brown KH. Impact of zinc supplementation on morbidity from diarrhea and respiratory infections among rural Guatemalan children. Pediatrics 1997; 99(6):808-813.

8.Alarcon P, Montoya R, Rivera J, Perez F, Peerson JM, Brown KH. Effect of inclusion of beans in a mixed diet for the treatment of Peruvian children with acute watery diarrhea. Pediatrics 1992;68:58-65.

9. Lanata CF, Black RE, C reed-Kanashiro H, Lazo F, Gallardo ML,Verastegui $\mathrm{H}$ et al. Feeding during acute diarrhea as a risk factor or persistent diarrhea. Acta Paediatr Scand 1992 (suppl);381:98-103.

10. Brown KH, Perez F, Gastañaduy AS. Clinical trial of modified whole milk, lactose-hydrolyzed whole milk, or cereal-milk mixtures for the dietary management of acute childhood diarrhea. J Pediatr Gastroenterol N utr 1991;12:340-350.

11. Black RE, Brown KH, Becker S, Alim AR, Merson MH. Contamination of weaning foods and transmission of enterotoxigenic Escherichia coli diarrhoea in children in rural Bangladesh. Trans R Soc Trop Med Hyg 1982; 76:259-264

12. Black RE, Lopez de Romaña G, Brown KH, Bravo N , Bazalar O G, Creed$\mathrm{K}$ anashiro $\mathrm{H}$. Incidence and etiology of infantile diarrhea and major routes of transmission in Huascar, Peru.Am J Epidemiol 1989;129:785-799.

13. Henry FJ, Patawary Y, Huttly SR, Aziz KM. Bacterial contamination of weaning foods and drinking water in rural Bangladesh. Epidemiol Infect 1990;104:79-85. 
14. $00 \mathrm{KN}$, Han AM, Hlaing T, Aye T. Bacteriological studies of food and water consumed by children in Myanmar, 1:The nature of contamination. J Diarrhoeal Dis Res 1991;9:87-90.

15. Brown K, Black RE, Lopez de Romana, Creed de Kanashiro H. Infant feeding practices and their relationship with diarrheal and other diseases in Huascar (Lima) Peru. Pediatrics 1989;83:31-40.

16. Black RE, Merson MH, Rahman AS, Yunus M, Alim AR, Huq I et al. A two-year study of bacterial viral, and parasitic agents associated with diarrhea in rural Bangladesh. J Inf D is 1980;142:660-664.

17. Huilan S, Zhen LG, Mathan MM, Mathew MM, 0 larte J, Espejo R et al. Etiology of acute diarrhoea among children in developing countries:A multicentre study in five countries. Bull W orld Health 0 rgan 1991;69:549-555. 18. Guerrant RL, Kirchoff LV, Shields DS, N ations MK, Leslie J, de So usa $M A$ et al. Prospective study of diarrheal illness in Northeastern Brazil: Patterns of disease, nutritional impact, etiologies and risk factors. J Infect $D$ is $1983 ; 148: 986-997$

19. Levine MM, Losonsky G, Herrington D. Pediatric diarrhea:The challenge of prevention. Pediatr Infect D is | 1986; 5(suppl):S29-43.

20. G lass R, Svennerholm A M, Sto II BJ, Khan MR, H ossain KM, Huq MI et al. Protection against cholera in breast-fed children by antibodies in breast milk. N Engl J Med 1983;308:1389-1392.

21. Atkinson SA, H anson LA, Chandra RK. Breast-feeding, nutrition, infection and infant growth in developed and emerging countries. St. John's, N ewfoundland:ARTS Biomedical Publishers and Distributors, 1990.

22. Cruz JR, Gil L, C ano F, Caceres P, Pareja G. Breast milk anti- Escherichia coli heat-labile toxin IgA antibodies protect against toxin-induced infantile diarrhea. Acta Paediatr Scand 1988;77:658-62.

23. Kim K, Pickering LK, D uPont HL, Sullivan N, W ilkins T. In vitro and in vivo neutralizing activity of human colostrum and milk against purified toxins A and B of Clostridium difficile. I Infect D is 1984;150;57-62.

24. Svennerholm AM, Jertborn $M, G$ othefors $L$, Karim $A M$, Sack DA, Holmgren J et al. Mucosal antitoxic and antibacterial immunity after cholera disease and after immunization with combined B subunit of whole cell vaccine.J Infect $D$ is 1984;149:884-893.

25. Svennerholm AM, A hren $C$, W enneras $C$ et al. D evelopment of an oral vaccine against enterotoxigenic Escherichia coli diarrhea. In:W adstrom $T$, Svennerholm AM, Makela $\mathrm{H}$ et al ed. Molecular pathogenesis of gastrointestinal infections. N ew York: Plenum Press, 1991:287-294.

26. Czerkinsky C, Svennerholm AM, Holmgren J. Induction and assessment of immunity at enteromucosal surfaces in humans: Implications for vaccine development. Clin Infect D is 1993;16 suppl 2:S106-S116.

27. Clemens JD, Stanton B, Stoll B, Shahid N S, Banu H, Chowdhury AK. Breast-feeding as a determinant of severity in shigellosis: Evidence for protection throughout the first three years of life in Bangladeshi children. Am J Epidemiol 1986;123:710-719.

28. Clemens JD, Sack D, H arris J, Khan MR, C hakraborty J, ChowdhuryAK et al. Breast-feeding and risk of severe cholera in rural Bangladeshi children. Am J Epidemiol 1990;131:400-412.

29. Hanson LA, Carlsson B, Jalil F. Antiviral and anti-bacterial factors in human milk. In: $\mathrm{H}$ anson LA ed. Biology of human milk. N ew York : Raven Press, 1988:141-157.

30. Cruz JR, C arlsson B, Garcia B, G ebre-Medhin M, Hofrander Y, U rrutia IJ et al. Studies on human milk III. Secretory IgA quantity and antibody levels against Escherichia coli in colostrum and milk from underprivileged and privileged mothers. Pediatr Res 1982;16:272-276.

31. 0 gra SS, 0 gra PL. Immunological aspects of human colostrum and milk I. D istribution characteristics and concentrations of immunoglobulin at different times after the onset of lactation.J Pediatr 1978:5:450-454. 32. Stoll BJ, Svennerholm AM, G othefors L, Barua D, Huda S, Holmgren J. Local and systemic antibody response to naturally acquired Escherichia coli diarrhea in an endemic area. J Infect D is 1986;153:527-533.
33. Tacket C O, Losonsky G, Link H, H oang Y, G uesrey P, Hilpert H. Protection by milk immunoglobulin concentrate against oral challenge with enterotoxigenic Escherichia coli. N Engl J Med 1987;318:1240-1243.

34. Long KZ, W ood J,Vasqez G aribay E,W eiss KM, Mathewson J], D uPont $\mathrm{HL}$ et al. Proportional hazards analysis of diarrhea due to enterotoxigenic Escherichia coli and breast-feeding in a cohort of Mexican children. Am J Epidemiol 1994;139:193-205.

35. Sack DA, Sack RB. Test for enterotoxigenic Escherichia coli using Y-1 adrenal cells in mini-culture. Infect Immun 1975;11:334-336.

36. Heckman J,W Walker J.U sing goodness of fit and other criteria to choose among competing duration models: A case study of Hutterite data. In: Clogg $C$, ed. Sociological methodology. N ew York, American Sociological Assoc, 1987.

37. Heckman JJ, Singer B. Social science duration analysis. In: Heckman J, Singer $\mathrm{B}$, ed. Longitudinal analysis of market data. Cambridge: $\mathrm{C}$ ambridge University Press, 1985.

38. Steinberg J. CTM:A user's guide. Unpublished manuscript, San Diego, University of C alifornia, 1991

39. Barrel RAE, Rowland GM. Infant foods as a potential source of diarrhoeal illness in rural W est Africa.Trans R Soc Trop Med Hyg1979;73:8590.

40. Motarjemi Y, Kafertein F, Moy G, Q uevedo F. Contaminated weaning food:A major risk factor for diarrhoea and associated malnutrition. Bull W orld Health 0 rgan 1993;71:79-92.

41.W alterspiel JN , Morrow AL, G uerrero ML, Ruiz-Palacios G M, Pickering LK. Secretory anti-Giardia lamblia antibodies in human milk: Protective effect against diarrhea. Pediatrics 1994;93:28-31.

42. Duke J. Isthmian Ethnobotanical Dictionary. Jodhpur: Scientific Publishers, 1986:220.

43. D uPont HL, Hornick RB.A dverse effect of Lomotil therapy in shigellosis. JAMA 1973; 226:1525-1528.

44.A hren CM, Svennerholm AML. Synergistic protective effect of antibodies against Escherichia coli enterotoxin and colonization factor antigens. Infect Immun 1982;74-79.

45. Klipstein FA, Engert RF, Clements JD. Protection in rats immunized with Escherichia coli enterotoxin. Infec Immun 1981;34:637-639.

46.The C ebu Study Team. Underlying and proximate determinants of child health:The Cebu Longitudinal Health and N utrition Study.Am J Epidemiol 1991;133:185-201.

47. Esrey SA, Habicht JP. Maternal literacy modifies the effect of toilets and piped water on infant survival in Malaysia. Am J Epidemiol 1988;127: 1079-1087.

48. Mota-Hernández F, Bross-Soriana D, Pérez-Ricárdez M,Velásquez-Jones L. Rice solution and World Health $O$ rganization solution by gastric infusion for high stool output diarrhea.AJDC 1991;145:937-940.

49. Gore SM, Fontaine 0 , Pierce $N$. Impact of rice based oral hydration solution on stool output and duration of diarrhoea: meta-analysis of 13 clinical trials. BMJ 1992;304:287-291.

50. W apnir R, Lifshitz F. 0 smolality and solute concentration -Their relationship with oral hydration solution effectiveness: An experimental assessment. Pediatr Res 1985;19:894-898.

51. Mahalanabis D, Alam AN, Rahman N, Hasnat A. Prognostic indicators and risk factors for increased duration of acute diarrhoea and for persistent diarrhoea in children. Int J Epidemiol 1991;20:1064-1072.

52. Baqui AH, Sack RB, Black RE, Haidar K, Hossain A, Alim AR et al. Enteropathogens associated with acute and persistent diarrhea in Bangladesh children less than 5 years of age. J Infect D is 1992;166:792-796.

53. C heckley W, G ilman RH, Epstein LD, Suarez M, D iaz JF, C abrera L et al. Asymptomatic and symptomatic cyptosporidiosis: Their acute effect on weight gain in Peruvian children. Am J Epidemiol 1997;145:156-163. 